\title{
Next-Generation Sequence Analysis of Genes Associated with Obesity and Nonalcoholic Fatty Liver Disease-Related Cirrhosis in Extreme Obesity
}

\author{
Glenn S. Gerhard ${ }^{\mathrm{a}, \mathrm{b}}$ Xin Chu ${ }^{\mathrm{a}} \quad$ G. Craig Wood ${ }^{\mathrm{a}}$ Genevieve M. Gerhard \\ Peter Benottic Anthony T. Petrick ${ }^{a}$ Jon Gabrielsen ${ }^{a} \quad$ William E. Strodel $^{a}$ \\ Christopher D. Stilla George Argyropoulos ${ }^{a}$ \\ ${ }^{a}$ Geisinger Obesity Research Institute, Geisinger Clinic, Danville, Pa., b Penn State Institute for Personalized Medicine, \\ Hershey, Pa., and 'St. Francis Medical Center, Trenton, N.J., USA
}

\section{Key Words}

Extreme obesity - Nonalcoholic fatty liver disease .

Cirrhosis - Genome-wide association studies .

Whole-exome sequencing

\begin{abstract}
Objectives: Genome-wide association studies (GWAS) have led to the identification of single nucleotide polymorphisms in or near several loci that are associated with the risk of obesity and nonalcoholic fatty liver disease (NAFLD). We hypothesized that missense variants in GWAS and related candidate genes may underlie cases of extreme obesity and NAFLDrelated cirrhosis, an extreme manifestation of NAFLD. Methods: We performed whole-exome sequencing on 6 Caucasian patients with extreme obesity [mean body mass index (BMI) 84.4] and 4 obese Caucasian patients (mean BMI 57.0) with NAFLD-related cirrhosis. Results: Sequence analysis was performed on 24 replicated GWAS and selected candidate obesity genes and 5 loci associated with NAFLD. No missense variants were identified in 19 of the 29 genes analyzed, although all patients carried at least 2 missense variants in the remaining genes without excess homozygosity. One patient with extreme obesity carried 2 novel damaging mutations in BBS1 and was homozygous for benign and
\end{abstract}

\section{KARGER}

() 2013 S. Karger AG, Basel

0001-5652/13/0754-0144\$38.00/0

E-Mail karger@karger.com

www.karger.com/hhe damaging MC3R variants. In addition, 1 patient with NAFLDrelated cirrhosis was compound heterozygous for rare damaging mutations in PNPLA3. Conclusions: These results indicate that analyzing candidate loci previously identified by GWAS analyses using whole-exome sequencing is an effective strategy to identify potentially causative missense variants underlying extreme obesity and NAFLD-related cirrhosis.

(c) 2013 S. Karger AG, Basel

\section{Introduction}

Based upon heritability and linkage studies, genetic variation plays a strong role in obesity $[1,2]$ and related comorbid conditions including nonalcoholic fatty liver disease (NAFLD) [3]. Recently, genome-wide association studies (GWAS) have identified single nucleotide polymorphisms (SNPs) in or near a number of genes that are related to increased body mass index (BMI) [4-6] as well as NAFLD [7]. However, the designs used in most GWAS only address the common variant-common disease hypothesis, and while they have revealed new pathways leading to obesity, they do have limitations [8] and do not address the role of rare variants. Mutations have been ob- 
served in certain families with extreme obesity [9], and rare variants located in genes responsible for familial obesity have been identified in sporadic patients with extreme obesity [10]. We and others have found rare variants in sporadic cases of extreme obesity in genes that have previously been associated with monogenic obesity $[11,12]$.

The common variants associated with obesity and NAFLD identified through GWAS have relatively small effect sizes. In contrast, rare variants are more likely to have direct functional consequences and a larger impact on the obesity and NAFLD phenotypes [13]. Rare alleles may also be useful for providing additional and novel insights into the mechanisms underlying the etiology of obesity and NAFLD [10]. The common variants found to be associated with obesity and NAFLD through GWAS are also for the most part located in intergenic or intronic regions; thus, they are assumed to serve only as markers that are linked to a given gene or region. Further mapping studies may be needed to identify the underlying causative variants. Lower frequency and missense genetic variants are not well represented in most commercial GWAS platforms, but are accessible through direct sequencing approaches. In addition, different study designs may be used to identify rare variants. Individuals who are at the extreme of the BMI distribution are ideal for such studies [14] since individuals at the extremes of BMI have been reported to carry a higher burden of obesity risk alleles [15].

We hypothesized that missense mutations in candidate genes previously identified through GWAS associated with obesity and NAFLD may be present in patients with extreme obesity as well as nonalcoholic steatohepatitis (NASH)-related cirrhosis, the most advanced manifestation of NAFLD. Here, we used next-generation whole-exome sequencing of an extreme trait design to identify variants in candidate genes shown by GWAS to be associated with obesity and NAFLD, as well as selected candidate genes in known obesity- and NAFLD-related pathways.

\section{Methods}

\section{Study Population}

Patients were recruited through the Geisinger Medical Center for Nutrition and Weight Management and were prospectively enrolled into a clinical research program in obesity. The research was approved by the Institutional Review Board of the Geisinger Clinic and all patients provided informed consent. A total of 6 of the heaviest nondiabetic patients (BMI range 78.5-94.3) on whom
DNA was available and 4 extremely obese patients (BMI range 52-66) with cirrhosis related to NAFLD were selected from a cohort of over 2,000 patients on whom a database of clinical variables was available [16]. Only Caucasians of clinically determined European descent were included; non-Caucasians comprised approximately $3 \%$ of the initial study population and were excluded. Genomic DNA was isolated from patient whole-blood samples as previously described [17].

\section{Whole-Exome Sequencing}

A total of $5 \mu \mathrm{g}$ of DNA per sample at a concentration of $\geq 100$ $\mathrm{ng} / \mu \mathrm{l}$ with a A260/A280 of $\geq 1.8$ and passing quality and concentration analysis using a $1 \%$ agarose gel was sent for sequencing to Perkin Elmer DNA Sequencing and Analysis Services (Branford, Conn., USA). The Agilent SureSelect Human All Exon was used for target enrichment. Sequencing of paired-end libraries was performed using a Illumina HiSeq 2000 Sequencer. The sequencing chemistry used was the Illumina cBot clustering chemistry version 1.0 and Illumina HiSeq chemistry version 1.0.

\section{Data Analysis}

The human genome version 37.1 was used as the reference sequence. Alignment indexing and reference-based mapping was performed using BWA version 0.5.8c. SAM to BAM conversion, sorting and indexing of BAM files, and variant calling were performed using SAMtools version 0.0.11. Coverage metrics were calculated using GATK version 1.0.3825. The pileup (variant calls) file was filtered to only include variants called with a mapping quality $\geq 20$.

Both Geospiza GeneSifter software and Integrated Genome Viewer 2.1 (Broad Institute) were used for annotation, visualization, and result filtering. Genes replicated in previous GWAS, including fat mass and obesity-associated (FTO) gene, melanocortin 4 receptor $(M C 4 R)$, transmembrane protein 18 (TMEM18), glucosamine-6-phosphate deaminase 2 (GNPDA2), brain-derived neurotrophic factor $(B D N F)$, neuronal growth regulator 1 (NEGR1), SH2B adaptor protein 1 (SH2B1), ets variant 5 (ETV5), mitochondrial carrier 2 (MTCH2), and potassium channel tetramerization domain-containing 15 (KCTD15) [4], were analyzed for nonsynonymous variants, as well as several genes associated with obesity phenotypes/pathways, including melanocortin 3 receptor $(M C 3 R)$ [18], melanocortin 1 receptor (MC1R) [19], leptin $(L E P)$ and leptin receptor (LEPR) [9], and the family of BardetBiedl syndrome $(B B S)$ genes $(B B S 1-12)$ of which the phenotypic spectrum in patients with $B B S 1$ mutations includes severe obesity [20]. We also analyzed genes previously implicated in NAFLD through GWAS, including patatin-like phospholipase domaincontaining 3 (PNPLA3), protein phosphatase 1, regulatory subunit 3B (PPP1R3B), neurocan (NCAN), lysophospholipase-like 1 (LYPLAL1), and glucokinase (GCK) [7]. Gene sifter software was used for variant calling followed by manual curation of each patient's alignments using Integrated Genome Viewer 2.1. PolyPhen-2 (Polymorphism Phenotyping version 2) and PROVEAN (Protein Variation Effect Analyzer version 1.1) were used to predict potential impact of an amino acid substitution on the structure and function of the corresponding protein using amino acid sequences from UniProtKB/UniRef100 (release December 14, 2011), structures from PDB/DSSP Snapshot (release January 3, 2012; 78,304 entries), and UCSC MultiZ multiple alignments of 45 vertebrate genomes with hg19/GRCh37 human genome (release Oc- 
tober 8,2009$)$. PolyPhen-2 calculates a Bayes posterior probability that a given mutation is damaging [21], while PROVEAN computes a delta alignment score based upon sequence identity [22]. We used the HumDiv score report, which estimates the chance that the mutation is classified as damaging when it is indeed damaging as classified against known mutations in the selected databases.

\section{Results}

\section{Patient Data}

We performed whole-exome sequencing on 6 Caucasian patients with extreme obesity with a mean BMI of 84.4 (range 78.5-94.3) and a weight range of 220-274 kg, representing the far extreme of the human body weight distribution (table 1). Samples from 4 patients with NAFLD-related cirrhosis were also sequenced. The melanocortin 4 receptor (MC4R) genes of all of these patients had been previously sequenced [11] and found to not contain any nonsynonymous variants, thereby excluding this common genetic form of obesity [23].

\section{Sequence Statistics}

The number of sequence reads that were evaluable for mapping ranged from just over 65 million to over 81 million (table 2). The number that were mapped to the reference genome ranged from just over 63 million to over 80 million or at least $97 \%$ of the total number of reads. The average percentage of mapped reads was $97.8 \%$, slightly greater than the $96.6 \%$ previously reported for Agilent target enrichment [24]. All coding regions of the selected genes had sequence coverage, except for the first coding exons of the FTO, BDNF, SH2B1, and MTCH2 genes. After filtering for $>8 \times$ coverage, just over 45,000 potential missense and nonsense variants were identified in the 10 patients, with $>80 \%$ already present in SNP databases. The extent of this number of single nucleotide variations is consistent with recent data from the 1000 Genomes Project [16].

\section{Sequence Data}

Sequence data from the patients with extreme obesity was analyzed for novel and for known single nucleotide variations resulting in missense mutations as well as splice site mutations and insertions and deletions that could cause frame shift and premature termination in the FTO, TMEM18, GNPDA2, BDNF, NEGR1, SH2B1, MTCH2, KCTD15, POMC, LEP, LEPR, MC3R, MC1R, and the known $B B S$ genes. Known and novel missense variants are shown in table 3. All patients carried at least 1 variant that had been previously reported in the NIH
Table 1. Sex, age, weight, BMI, and steatosis grade of the patients sequenced

\begin{tabular}{rllllll}
\hline ID & Phenotype & Sex & $\begin{array}{l}\text { Age, } \\
\text { years }\end{array}$ & $\begin{array}{l}\text { Weight, } \\
\text { kg }\end{array}$ & & $\begin{array}{l}\text { Steatosis } \\
\text { grade }\end{array}$ \\
\hline 1 & Extreme obesity & $\mathrm{m}$ & 38 & 274 & 94 & \\
2 & Extreme obesity & $\mathrm{m}$ & 44 & 268 & 88 & \\
3 & Extreme obesity & $\mathrm{f}$ & 40 & 238 & 85 & \\
4 & Extreme obesity & $\mathrm{f}$ & 31 & 233 & 81 & \\
5 & Extreme obesity & $\mathrm{m}$ & 54 & 255 & 80 & \\
6 & Extreme obesity & $\mathrm{f}$ & 31 & 220 & 78 & \\
7 & NASH cirrhosis & $\mathrm{f}$ & 29 & 169 & 66 & 2 \\
8 & NASH cirrhosis & $\mathrm{m}$ & 46 & 163 & 55 & 2 \\
9 & NASH cirrhosis & $\mathrm{m}$ & 47 & 179 & 55 & 3 \\
10 & NASH cirrhosis & $\mathrm{f}$ & 48 & 143 & 52 & 2 \\
\hline
\end{tabular}

Table 2. Next-generation mapping statistics

\begin{tabular}{rlll}
\hline ID & Reads (total) & Reads mapped (to ref.) & Percent mapped \\
\hline 1 & 69342956 & 67877372 & 97.9 \\
2 & 65048252 & 63691045 & 97.9 \\
3 & 75846164 & 74474414 & 98.2 \\
4 & 81683500 & 80069569 & 98.0 \\
5 & 76541344 & 74905894 & 97.9 \\
6 & 69704186 & 68216525 & 97.9 \\
7 & 70153196 & 68069847 & 97.0 \\
8 & 75783488 & 73999386 & 97.6 \\
9 & 74423584 & 72680786 & 97.7 \\
10 & 78391494 & 76990308 & 98.2 \\
\hline
\end{tabular}

dbSNP database and assigned a reference SNP ('rs') ID number variant in at least 1 of these genes. Five of the 6 patients carried at least 1 novel variant in at least 1 of the genes, which included the BBS1, BBS4, MC1R, NEGR11, and TMEM18 genes. One MC1R variant, the TMEM variant, and both $B B S 1$ variants were predicted to be moderately to severely damaging by both PolyPhen- 2 and PROVEAN analyses, while the other novel variants were predicted to be benign. A relatively low-frequency benign $M C 3 R$ variant was found in 3 patients and 1 rare $M C 3 R$ damaging variant was found in 1 of these patients. Interestingly, no missense variants were found in the FTO, GNPDA2, BDNF, MTCH2, KCTD15, POMC, LEP, and the other $B B S$ genes.

Five of the 6 patients were homozygous for at least 1 variant, although the gene frequencies of the $B B S 4$ and $S H 2 B 1$, and $1 M C 1 R$ and $L E P R$ homozygous variant, were greater than 0.35 in the HapMap CEU population. Five of 
Table 3. Sequence variants predicted to result in nonsynonymous amino acid substitutions identified by wholeexome sequencing in patients with extreme obesity

\begin{tabular}{|c|c|c|c|c|c|c|c|}
\hline ID & Gene & $\begin{array}{l}\text { Missense } \\
\text { variant }\end{array}$ & rs number & $\begin{array}{l}\text { CEU allele } \\
\text { frequency }\end{array}$ & Zygosity & $\begin{array}{l}\text { PolyPhen } \\
\text { score }^{1}\end{array}$ & $\begin{array}{l}\text { PROVEAN } \\
\text { score }^{2}\end{array}$ \\
\hline \multirow[t]{2}{*}{1} & $M C 1 R$ & V92M & rs2228479 & 0.066 & $\mathrm{~h}$ & 0.053 & -0.53 \\
\hline & $M C 1 R$ & R163Q & rs885479 & 0.08 & $\mathrm{~h}$ & 0.015 & -0.42 \\
\hline \multirow[t]{5}{*}{2} & BBS4 & $\mathrm{K} 454 \mathrm{~N}$ & novel & - & $\mathrm{h}$ & 0.004 & -0.01 \\
\hline & $L E P R$ & Q223R & rs1137101 & 0.55 & $\mathrm{H}$ & 0.20 & -1.27 \\
\hline & $L E P R$ & K656N & rs8179183 & 0.10 & $\mathrm{~h}$ & 0.224 & -0.07 \\
\hline & $M C 1 R$ & R162G & novel & - & $\mathrm{h}$ & 0.001 & 0.36 \\
\hline & $M C 1 R$ & R163Q & rs885479 & 0.08 & $\mathrm{~h}$ & 0.015 & -0.42 \\
\hline \multirow[t]{8}{*}{3} & BBS4 & $\mathrm{I} 354 \mathrm{~T}$ & rs2277598 & 0.78 & $\mathrm{H}$ & 0.001 & -0.18 \\
\hline & $L E P R$ & Q223R & rs1137101 & 0.55 & $\mathrm{H}$ & 0.20 & -1.27 \\
\hline & $L E P R$ & K656N & rs8179183 & 0.10 & $\mathrm{~h}$ & 0.224 & -0.07 \\
\hline & $M C 1 R$ & R162G & novel & - & $\mathrm{h}$ & 0.001 & 0.36 \\
\hline & $M C 1 R$ & R163Q & rs885479 & 0.08 & $\mathrm{~h}$ & 0.015 & -0.42 \\
\hline & $M C 3 R$ & V44I & rs3827103 & 0.11 & $\mathrm{~h}$ & 0.098 & -0.14 \\
\hline & $S H 2 B 1$ & $\mathrm{~T} 484 \mathrm{~A}$ & rs7498665 & 0.36 & $\mathrm{H}$ & 0.00 & 0.05 \\
\hline & TMEM18 & D22G & novel & - & $\mathrm{h}$ & 0.999 & -6.23 \\
\hline \multirow[t]{8}{*}{4} & $B B S 4$ & $\mathrm{I} 354 \mathrm{~T}$ & rs2277598 & 0.78 & $\mathrm{~h}$ & 0.001 & -0.18 \\
\hline & $B B S 4$ & $\mathrm{~K} 454 \mathrm{~N}$ & novel & - & $\mathrm{h}$ & 0.004 & -0.01 \\
\hline & $L E P R$ & Q223R & rs1137101 & 0.55 & $\mathrm{~h}$ & 0.20 & -1.27 \\
\hline & $L E P R$ & K656N & rs8179183 & 0.10 & $\mathrm{~h}$ & 0.224 & -0.07 \\
\hline & $M C 1 R$ & R151C & rs1805007 & 0.057 & $\mathrm{~h}$ & 0.993 & -7.37 \\
\hline & $M C 1 R$ & R163Q & rs885479 & 0.08 & $\mathrm{H}$ & 0.015 & -0.42 \\
\hline & $M C 3 R$ & V44I & rs3827103 & 0.11 & $\mathrm{~h}$ & 0.098 & -0.14 \\
\hline & SH2B1 & $\mathrm{T} 484 \mathrm{~A}$ & rs7498665 & 0.36 & $\mathrm{H}$ & 0.00 & 0.05 \\
\hline \multirow[t]{6}{*}{5} & $B B S 4$ & $\mathrm{I} 354 \mathrm{~T}$ & rs2277598 & 0.78 & $\mathrm{~h}$ & 0.001 & -0.18 \\
\hline & $B B S 4$ & $\mathrm{~K} 454 \mathrm{~N}$ & novel & - & $\mathrm{h}$ & 0.004 & -0.01 \\
\hline & $L E P R$ & Q223R & rs1137101 & 0.55 & $\mathrm{H}$ & 0.20 & -1.27 \\
\hline & $M C 1 R$ & R163Q & rs885479 & 0.08 & $\mathrm{H}$ & 0.015 & -0.42 \\
\hline & $M C 1 R$ & D294A & novel & - & $\mathrm{h}$ & 1.000 & -6.65 \\
\hline & $S H 2 B 1$ & $\mathrm{~T} 484 \mathrm{~A}$ & rs7498665 & 0.36 & $\mathrm{~h}$ & 0.00 & 0.05 \\
\hline \multirow[t]{10}{*}{6} & $B B S 1$ & $\mathrm{I} 274 \mathrm{~F}$ & novel & - & $\mathrm{h}$ & 0.432 & -1.37 \\
\hline & $B B S 1$ & V355G & novel & - & $\mathrm{h}$ & 0.963 & -6.27 \\
\hline & $B B S 4$ & I354T & rs2277598 & 0.78 & $\mathrm{~h}$ & 0.001 & -0.18 \\
\hline & $L E P R$ & Q223R & rs1137101 & 0.55 & $\mathrm{H}$ & 0.20 & -1.27 \\
\hline & $L E P R$ & K656N & rs8179183 & 0.10 & $\mathrm{~h}$ & 0.224 & -0.07 \\
\hline & $M C 3 R$ & V44I & rs3827103 & 0.11 & $\mathrm{~h}$ & 0.098 & -0.14 \\
\hline & $M C 3 R$ & R220S & rs61735259 & - & $\mathrm{h}$ & 0.92 & -2.55 \\
\hline & $M C 1 R$ & R163Q & rs885479 & 0.08 & $\mathrm{~h}$ & 0.015 & -0.42 \\
\hline & NEGR1 & Y347S & rs41289154 & - & $\mathrm{h}$ & 0.96 & -1.13 \\
\hline & $S H 2 B 1$ & $\mathrm{~T} 484 \mathrm{~A}$ & rs7498665 & 0.36 & $\mathrm{~h}$ & 0.00 & 0.05 \\
\hline
\end{tabular}

$\mathrm{H}=$ Homozygous; $\mathrm{h}=$ heterozygous.

${ }^{1}$ Probability that a given missense substitution is damaging. ${ }^{2}$ Score $<-1.3$ indicates damaging substitution.

the 6 patients were compound heterozygotes for $M C 1 R$ variants (the 6 th a heterozygote), while 4 of 6 were compound heterozygous for LEPR variants (a 5th heterozygous). Two patients were compound heterozygous for $B B S 4$ variants (3 more heterozygous). One patient carried
2 novel BBS1 variants suggesting compound heterozygosity, although we cannot determine whether the 2 variants are in a cis versus trans configuration.

Sequence data from the patients with NASH-related cirrhosis were analyzed for novel and known missense 
Table 4. Sequence variants predicted to result in nonsynonymous amino acid substitutions identified by wholeexome sequencing in patients with NASH-related cirrhosis

\begin{tabular}{lllllllr}
\hline ID & Gene & Missense & rs number & $\begin{array}{l}\text { CEU allele } \\
\text { frequency }\end{array}$ & Zygosity & $\begin{array}{l}\text { PolyPhen } \\
\text { score }\end{array}$ & $\begin{array}{l}\text { PROVEAN } \\
\text { score }^{2}\end{array}$ \\
\hline 7 & GCKR & L446P & rs1260326 & - & $\mathrm{H}$ & 0.000 & 2.42 \\
& LYPLAL1 & I131M & rs940570 & - & $\mathrm{H}$ & 0.004 & 1.29 \\
\hline 8 & GCKR & L446P & rs1260326 & - & $\mathrm{h}$ & 0.00 & 2.42 \\
& LYPLAL1 & V144G & novel & & & 0.000 & -5.56 \\
& PNPLA3 & K434E & rs2294918 & 0.62 & $\mathrm{~h}$ & 0.000 & 0.19 \\
\hline 9 & PNPLA3 & I148M & rs738409 & 0.23 & $\mathrm{~h}$ & 0.98 & -2.57 \\
& PNPLA3 & V162M & rs141106484 & - & $\mathrm{h}$ & 0.974 & -2.23 \\
& PNPLA3 & K434E & rs2294918 & 0.62 & $\mathrm{~h}$ & 0.000 & 0.19 \\
\hline 10 & GCKR & L446P & rs1260326 & - & $\mathrm{h}$ & 0.000 & 2.42 \\
& LYPLAL1 & V144G & novel & - & $\mathrm{h}$ & 0.000 & -5.56 \\
& PNPLA3 & I148M & rs738409 & 0.23 & $\mathrm{~h}$ & 0.98 & -2.57 \\
\hline
\end{tabular}

$\mathrm{H}=$ Homozygous; $\mathrm{h}=$ heterozygous.

${ }^{1}$ Probability that a given missense substitution is damaging. ${ }^{2}$ Score $<-1.3$ indicates damaging substitution.

variants in the PNPLA3, PPP1R3B, NCAN, LYPLAL1, and GCK genes. Known and novel missense variants are shown in table 4 . All patients carried at least 1 variant that had been previously reported in the NIH dbSNP database in at least 1 of these genes. Two of the 4 patients carried a novel variant in the LYPLAL1 gene, which was predicted to be benign by PolyPhen. Known variants were identified in the GCKR, LYPLAL1, and PNPLA3 genes. One patient was compound heterozygous for 3 PNPLA3 variants, 2 of which were predicted to be severely damaging mutations.

\section{Discussion}

A number of loci have been identified through GWAS to be associated with obesity. No studies to date have systematically analyzed these GWAS obesity genes for missense variants in obese patients. We employed a wholeexome next-generation sequencing strategy using an extreme-trait design. The power of whole-exomesequencing lies in the efficiency with which specific genes may be analyzed simultaneously, rather than a gene-by-gene approach. However, because our study was not sufficiently powered to demonstrate statistical association of new or novel genes and variants, we restricted analysis to genes previously demonstrated to be associated with obesity and NAFLD. The extreme-trait design was used to in- crease the power to enrich for rare obesity risk alleles [14]. Although other studies have followed a similar design $[10,15,25,26]$, ours is the first to use whole-exome sequencing for extreme obesity.

No missense variants were identified in the FTO, GNPDA2, BDNF, MTCH2, KCTD15, POMC, LEP, and BBS2, $B B S 3$, or $B B S 5-12$ genes. These results have potential implications for the potential roles of the SNPs associated with obesity identified by GWAS, as well as the obesity candidate genes we analyzed. Without linkage to missense variants, at least in patients with extreme obesity, the GWAS SNPs rather may play roles in the regulation of gene expression. These roles could be complex, such as disrupting transcription factor binding sites, altering expression of microRNAs, etc. The recent data generated from the ENCODE project [27] may be useful in helping to identify the functional effects of the GWAS SNPs not linked to missense variants. Similar issues pertain to the absence of missense variants in obesity candidate genes. Most of the obesity genes are thought to play a role in the central nervous system, further complicating mechanistic studies. In addition to $M C 4 R, M C 3 R, L E P, L E P R$, and $P O M C$, the GWAS genes FTO, TMEM18, KCTD15, $S H 2 B 1, G N P D A 2$, and NEGR1 are expressed at high levels in the brain and hypothalamus [4].

Despite the lack of missense variants in a number of the genes, 5 of the 6 patients with extreme obesity were homozygous for at least 1 missense variant, including 
known and common variants in BBS4 and SH2B1, 1 in $M C 1 R$, and 1 in $L E P R$. This was not surprising given the high frequencies for these known variants. Five of the 6 patients were compound heterozygotes for MC1R variants (the 6th a heterozygote). Although $M C 1 R$ is not known to be highly expressed in the central nervous system, it does exhibit expression in adipose tissue [28] and the liver [29], suggesting a potential role in obesity.

Novel and rare variants were found in the obesity candidate genes $B B S 1$ and $M C 3 R$. One patient carried a pair of novel damaging variants in the BBS1 gene and 1 novel damaging and 1 common nondamaging variant in the $M C 3 R$ gene. Available clinical data indicated that, in addition to severe obesity, this patient was diagnosed with, and being treated for, asthma, a relatively common manifestation of the ciliopathy disorder Bardet-Biedl syndrome [30, 31]. BBS proteins are involved in the function of cilia and likely contribute to asthma due to defects in the cilia of airway epithelium [32]. The obesity phenotype, another common feature of Bardet-Biedl syndrome, may be influenced by functional effects from both genes. Obesity in Bardet-Biedl syndrome is associated with a specific defect in leptin effects on $P O M C$ neurons [33]. In $P O M C$ neurons, leptin causes increased neuronal firing and concomitantly increased $P O M C$ gene expression, therefore increasing $\alpha-M S H$, an agonist of the melanocortin 3 receptor. In this patient, multiple affected components in this pathway may contribute to the pathogenesis of the extreme obesity phenotype.

Similar findings were found for 1 of the patients with NASH-related cirrhosis, who was compound heterozygous for the well-characterized I148M NAFLD predisposing variant in PNPLA3 [34] and a rare but damaging V162M variant in PNPLA3. Given the known association of the PNPLA3 I148M variant and fibrosis [35], this combination of 2 damaging mutations in the PNPLA3 gene is likely a strong predisposing factor for the development of this patient's NASH-related cirrhosis.

Despite its massively parallel nature, a variety of technical issues can affect next-generation sequencing analysis. Random drop-out, which can result when only 1 allele is selectively amplified, can result in allelic bias and artifactual homozygosity. Next-generation library preparation methods such as those used here employ such amplification steps [24]. Such low-frequency artifacts should be minimized with paired-end reads that we generated. We found that only $8 / 39$ of the obesity variants and $2 / 10$ of the NAFLD cirrhosis variants were homozygous. A potential bias in the opposite direction is enrichment for the reference sequence during the exon capture procedure

Whole-Exome Sequencing in Extreme Obesity resulting in false negatives, i.e. missing novel genetic variants because the variant will not hybridize as well to the capture oligonucleotide. The Agilent exon capture reagents consist of long oligonucleotides that are long enough to hybridize even in the context of significant mismatches. Another drawback to exome capture is that not all bases will be captured with equal efficiency. While variation across regions was apparent, we used minimum quality scores to exclude variants from low-coverage regions.

Our study was conducted only in patients with extreme obesity; thus, the findings may not be relevant to patients at lower, though still obese, BMI levels. Future studies employing larger sample sizes and individuals with normal body weights will be needed to establish the frequency and association of novel genes and variants with extreme obesity. Previous studies have found that individuals with extreme obesity carried more alleles associated with increased BMI [15], but that there was no evidence for homozygosity associating with extreme obesity, suggesting that extreme obesity constitutes a phenotypic extreme of the normal-weight population, and not a collection of isolated familial obesity syndromes. Our results are consistent with this observation. Thus, only 1 of the 6 patients with extreme obesity and 1 of the 4 cirrhotic patients had mutations that could be plausibly contributing to their extreme phenotypes. The novel variants we identified were also from individuals of European ancestry; thus, they may not be found in a non-Caucasian population.

Whole-exome sequencing also does not detect most structural variants, such as large deletions or duplications that may be relevant to extreme obesity, such as the previously reported $16 \mathrm{p} 11.2$ deletion [26]. The whole-exome capture step also only targets those sequences that are in the capture reagents. Potential variants lying within untargeted exons will not be identified. To overcome this limitation, whole-genome sequencing may be an alternative method. This approach uses total DNA and does not attempt to capture specific regions. However, the large amount of sequence data that must be generated increases the cost for the same amount of coverage of exonic regions. The additional nonexonic data are also difficult to interpret; exome data will contain the putative functional variants based on the increased likelihood of a missense mutation altering protein function.

The identification of low-frequency and novel missense variants in several GWAS and obesity genes suggests that whole-exome sequencing may be an effective strategy to identify novel missense variants associated 
with extreme obesity and related conditions. Knowledge of the genetic architecture of obesity and NAFLD may have several potential clinical implications, including identification of potential drug targets, stratification of clinical weight loss and NAFLD drug trials based upon genotype, and diagnostic tests. However, further determination of genotype and allele frequencies in larger cohorts is required. In addition, validation of these variants using orthogonal technologies, as well as in silico and/or in vitro and in vivo functional studies will be required to determine the potential role of these variants in extreme obesity.

\section{Acknowledgements}

This work was supported by funds from the Geisinger Clinic, the Weis Center for Research, the Geisinger Obesity Research Institute, and NIH grants DK072488 (G.S.G., C.D.S., G.A., and X.C.), DK088231 (G.S.G.), and DK091601 (G.S.G.). We gratefully acknowledge the extraordinary cooperation and support of the patients enrolled in the Geisinger Bariatric Surgery program without whom these studies would not have been possible.

\section{Disclosure Statement}

C.D.S. receives a grant and consulting support from EthiconEndosurgery. A.T.P. receives educational grants from Covidien and Ethicon-Endosurgery.

\section{References}

1 Hebebrand J, Sommerlad C, Geller F, Gorg T, Hinney A: The genetics of obesity: practical implications. Int J Obes Relat Metab Disord 2001;25(suppl 1):S10-S18.

$\checkmark 2$ Speakman JR: Obesity: the integrated roles of environment and genetics. J Nutr 2004;134: 2090S-2105S

-3 Anstee QM, Daly AK, Day CP: Genetics of alcoholic and nonalcoholic fatty liver disease. Semin Liver Dis 2011;31:128-146.

-4 Willer CJ, Speliotes EK, Loos RJ, Li S, Lindgren CM, et al: Six new loci associated with body mass index highlight a neuronal influence on body weight regulation. Nat Genet 2009;41:25-34.

$\checkmark 5$ Frayling TM, Timpson NJ, Weedon MN, Zeggini E, Freathy RM, et al: A common variant in the FTO gene is associated with body mass index and predisposes to childhood and adult obesity. Science 2007;316:889-894.

-6 Loos RJ, Lindgren CM, Li S, Wheeler E, Zhao $\mathrm{JH}$, et al: Common variants near MC4R are associated with fat mass, weight and risk of obesity. Nat Genet 2008;40:768-775.

7 Speliotes EK, Yerges-Armstrong LM, Wu J, Hernaez R, Kim LJ, et al: Genome-wide association analysis identifies variants associated with nonalcoholic fatty liver disease that have distinct effects on metabolic traits. PLoS Genet 2011; 7:e1001324.

8 Pearson TA, Manolio TA: How to interpret a genome-wide association study. JAMA 2008; 299:1335-1344.

-9 Ranadive SA, Vaisse C: Lessons from extreme human obesity: monogenic disorders. Endocrinol Metab Clin North Am 2008;37:733751.

10 Ahituv N, Kavaslar N, Schackwitz W, Ustaszewska A, Martin J, Hebert S, Doelle H, Ersoy B, Kryukov G, Schmidt S, Yosef N, Ruppin E, Sharan R, Vaisse C, Sunyaev S, Dent R, Cohen J, McPherson R, Pennacchio LA: Medical sequencing at the extremes of human body mass. Am J Hum Genet 2007;80:779-791.
11 Mirshahi UL, Still CD, Masker KK, Gerhard GS, Carey DJ, Mirshahi T: The MC4R(I251L) allele is associated with better metabolic status and more weight loss after gastric bypass surgery. JClin Endocrinol Metab 2011;96:E2088E2096.

12 Harismendy O, Bansal V, Bhatia G, Nakano M, Scott M, Wang X, Dib C, Turlotte E, Sipe JC, Murray SS, Deleuze JF, Bafna V, Topol EJ, Frazer KA: Population sequencing of two endocannabinoid metabolic genes identifies rare and common regulatory variants associated with extreme obesity and metabolite level. Genome Biol 2010;11:R118.

13 Gorlov IP, Gorlova OY, Frazier ML, Spitz MR, Amos CI: Evolutionary evidence of the effect of rare variants on disease etiology. Clin Genet 2011;79:199-206.

14 Cirulli ET, Goldstein DB: Uncovering the roles of rare variants in common disease through whole-genome sequencing. Nat Rev Genet 2010;11:415-425.

15 Cotsapas C, Speliotes EK, Hatoum IJ, Greenawalt DM, Dobrin R, Lum PY, Suver C, Chudin E, Kemp D, Reitman M, Voight BF, Neale BM, Schadt EE, Hirschhorn JN, Kaplan LM, Daly MJ: Common body mass index-associated variants confer risk of extreme obesity. Hum Mol Genet 2009;18:3502-3507.

16 Abecasis GR, Auton A, Brooks LD, DePristo MA, Durbin RM, Handsaker RE, Kang HM, Marth GT, McVean GA: An integrated map of genetic variation from 1,092 human genomes. Nature 2012;491:56-65.

17 Chu X, Erdman R, Susek M, Gerst H, Derr K, Al-Agha M, Wood GC, Hartman C, Yeager S, Blosky MA, Krum W, Stewart WF, Carey D, Benotti P, Still CD, Gerhard GS: Association of morbid obesity with FTO and INSIG2 allelic variants. Arch Surg 2008;143:235-240; discussion 241.
18 Mencarelli M, Dubern B, Alili R, Maestrini S, Benajiba L, Tagliaferri M, Galan P, Rinaldi M, Simon C, Tounian P, Hercberg S, Liuzzi A, Di Blasio AM, Clement K: Rare melanocortin-3 receptor mutations with in vitro functional consequences are associated with human obesity. Hum Mol Genet 2011;20:392-399.

19 Butler AA, Cone RD: The melanocortin receptors: lessons from knockout models. Neuropeptides 2002;36:77-84.

20 Guo DF, Rahmouni K: Molecular basis of the obesity associated with Bardet-Biedl syndrome. Trends Endocrinol Metab 2011;22: 286-293.

21 Adzhubei IA, Schmidt S, Peshkin L, Ramensky VE, Gerasimova A, Bork P, Kondrashov AS, Sunyaev SR: A method and server for predicting damaging missense mutations. Nat Methods 2010;7:248-249.

22 Choi Y, Sims GE, Murphy S, Miller JR, Chan AP: Predicting the functional effect of amino acid substitutions and indels. PLoS One 2012; $7: e 46688$

23 Farooqi IS: Monogenic human obesity. Front Horm Res 2008;36:1-11.

24 Clark MJ, Chen R, Lam HY, Karczewski KJ, Euskirchen G, Butte AJ, Snyder M: Performance comparison of exome DNA sequencing technologies. Nat Biotechnol 2011;29: 908-914.

25 Calton MA, Ersoy BA, Zhang S, Kane JP, Malloy MJ, Pullinger CR, Bromberg Y, Pennacchio LA, Dent R, McPherson R, Ahituv N, Vaisse C: Association of functionally significant melanocortin-4 but not melanocortin-3 receptor mutations with severe adult obesity in a large North American case-control study. Hum Mol Genet 2009;18:1140-1147.

26 Walters RG, Jacquemont S, Valsesia A, de Smith AJ, Martinet D, et al: A new highly penetrant form of obesity due to deletions on chromosome 16p11.2. Nature 2010;463:671675 . 
27 Dunham I, Kundaje A, Aldred SF, Collins PJ, Davis CA, et al: An integrated encyclopedia of DNA elements in the human genome. Nature 2012;489:57-74.

28 Hoch M, Eberle AN, Wagner U, Bussmann C, Peters T, Peterli R: Expression and localization of melanocortin-1 receptor in human adipose tissues of severely obese patients. Obesity (Silver Spring) 2007;15:40-49.

29 Gatti S, Colombo G, Turcatti F, Lonati C, Sordi A, Bonino F, Lipton JM, Catania A: Reduced expression of the melanocortin-1 receptor in human liver during brain death. Neuroimmunomodulation 2006;13:51-55.
30 Moore SJ, Green JS, Fan Y, Bhogal AK, Dicks E, Fernandez BA, Stefanelli M, Murphy C, Cramer BC, Dean JC, Beales PL, Katsanis N, Bassett AS, Davidson WS, Parfrey PS: Clinical and genetic epidemiology of Bardet-Biedl syndrome in Newfoundland: a 22-year prospective, population-based, cohort study. Am J Med Genet A 2005;132:352-360.

- 31 Cox KF, Kerr NC, Kedrov M, Nishimura D, Jennings BJ, Stone EM, Sheffield VC, Iannaccone A: Phenotypic expression of BardetBiedl syndrome in patients homozygous for the common M390R mutation in the BBS1 gene. Vision Res 2012;75:77-87.

-32 Shah AS, Farmen SL, Moninger TO, Businga TR, Andrews MP, Bugge K, Searby CC, Nishimura D, Brogden KA, Kline JN, Sheffield VC, Welsh MJ: Loss of Bardet-Biedl syndrome proteins alters the morphology and function of motile cilia in airway epithelia. Proc Natl Acad Sci USA 2008;105:33803385.
33 Zaghloul NA, Katsanis N: Mechanistic insights into Bardet-Biedl syndrome, a model ciliopathy. J Clin Invest 2009;119:428-437.

$34 \mathrm{He}$ S, McPhaul C, Li JZ, Garuti R, Kinch L, Grishin NV, Cohen JC, Hobbs HH: A sequence variation (I148M) in PNPLA3 associated with nonalcoholic fatty liver disease disrupts triglyceride hydrolysis. J Biol Chem 2010;285:6706-6715.

35 Sookoian S, Pirola CJ: Meta-analysis of the influence of $I 148 \mathrm{M}$ variant of patatin-like phospholipase domain containing 3 gene (PNPLA3) on the susceptibility and histological severity of nonalcoholic fatty liver disease. Hepatology 2011;53:1883-1894. 